\title{
EFFECTS OF CFRP LAMINATE THICKNESS ON THE BENDING AFTER IMPACT STRENGTH
}

\author{
Sören Nilsson ${ }^{1}$, Anders Bredberg ${ }^{2}$, and Leif E. Asp ${ }^{1,3}$ \\ ${ }^{1}$ Swerea SICOMP AB, Box 104, SE-431 22Mölndal, Sweden \\ ${ }^{2}$ Saab Aerostructures, SE-581 88 Linköping, Sweden \\ ${ }^{3}$ Div. of Polymer Engineering, Luleå University of Technology, SE-97187 Luleå, Sweden
}

\begin{abstract}
This paper describes a series of experiments set out to explore the strength of bending loaded impacted monolithic composite panels with different thicknesses. Due to the aim to decrease manufacturing cost future structures are expected to have a higher degree of integration and complexity. More integrated structures give fewer articles and fewer steps in the manufacturing chain. Also the maximum thickness of laminated composite structures is increasing in aircraft structures. For example, the wing spars of the inner wings as well as the central wing box in modern aircraft are made from composite laminates with thickness exceeding $40 \mathrm{~mm}$. As a consequence of this development there are more interlaminar loads (bending, transverse shear etc) within composite structures. Therefore the composite structures must sustain high out of plane loads (bending, transverse shear etc). To increase the potential and reduce conservatism during design there is a need to increase the knowledge regarding residual strength of out of plane loaded impact damaged composite structure. This study was launched as a first attempt to study the effects of bending load at different laminate thicknesses of a composite structure. Here two laminate thicknesses are tested, both exposed to the same impact threat. Accompanying tests in compression are performed and reported to allow evaluation of the full effects of bending. A limited fractographic analysis is also performed to study damage distribution after impact as well as after mechanical tests. It has been demonstrated that damage distribution through the thickness affects the bending properties of the laminate as the failure load was lower when the side with the largest delamination was loaded in compression. As expected it has also been demonstrated that the far field failure strain is higher at bending compared to compression loading.
\end{abstract}

\section{INTRODUCTION}

More and more composite materials are used within primary load carrying aircraft structures. Examples are Boeing 787 and Airbus A350XWB where the composite content has increased to 50-60\% by weight. As a reference the structural weight of the Saab Gripen fighter, depicted in Fig. 1, is approximately $25 \%$ by weight.

Due to the aim to decrease manufacturing cost the structures have a higher degree of integration and complexity. More integrated structures give fewer articles and fewer steps in the manufacturing chain. In many cases new innovative design solutions are a requirement to enable integrated structures. Good examples of this are Saab Aerostructures redesign of the A320 aileron (see Fig 1) and Boeing 787 "Bulk Cargo Door", where manufacturing cost has been reduced considerably partly due to this kind of innovative design solutions.

Also the maximum thickness of laminated composite structures is increasing in aircraft structures. For example, the wing spars of the inner wings as well as the central wing box in modern aircraft are made from composite laminates with thickness exceeding $40 \mathrm{~mm}$. 

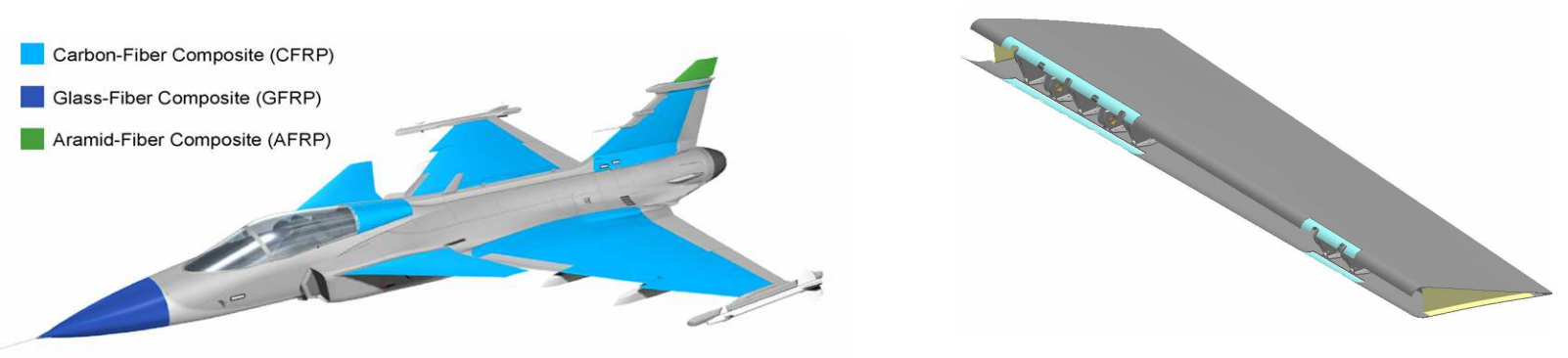

Fig. 1. The Saab Gripen fighter (left) and the A320 Aileron redesign (right).

As a consequence of this development there are more interlaminar loads (bending, transverse shear etc) within composite structures. Example of this is stringer stiffened panels (where the fasteners are substituted by matrix plastic as load carrier between skin and stringers), beam radii, areas with thickness variations, fuel pressure loads etc. Furthermore there is a strive to permit operation in the post-buckled regime, which also contributes to the out of plane loads.

Impact frequently causes damage on composite structures that may cause significant reduction in strength. Low velocity impact damage due to e.g. dropped tools, runway debris during fabrication or maintenance operations may cause so called "barely visible impact damage", BVID. This type of damage is often not visible to the naked eye and has to be observed by e.g. ultrasonic C-scan. Since there is a potential risk of undetected damage (BVID) in an aircraft structure these types of damage must be taken into consideration during design.

Traditionally the structures are designed to minimize out of plane loading, due to the composite material's low interlaminar strength. Because of this there is a lack of design tools and data that handles these loads. At Saab there exist for example extensive test results and a tool regarding residual strength of in-plane loaded composite structure. To increase the potential and reduce conservatism during design there is a need to increase the knowledge regarding residual strength of out of plane loaded impact damaged composite structure. The study presented in this work is one step towards this. Here two laminate thicknesses are tested in bending, both exposed to the same impact threat. Accompanying tests in compression are performed and reported to allow evaluation of the full effects of bending.

\section{EXPERIMENTS}

Saab Aerostructures manufactured laminates from HTA/6376C carbon fibre/epoxy prepreg, according to the Saab standard and test plan [1]. Two nominal laminate thicknesses were manufactured, $4.16 \mathrm{~mm}$ and $8.32 \mathrm{~mm}$ respectively. The plates were cut into specimens with a width of $156 \mathrm{~mm}$ and a length of $260 \mathrm{~mm}$ and $450 \mathrm{~mm}$ for compression and bending tests respectively. The specimens were clamped $(150 \times 230 \mathrm{~mm})$ and impacted in a drop-weight rig with $35 \mathrm{~J}$ using a spherical tup with a radius of $8 \mathrm{~mm}$.

After impact, the dent depth was measured by the use of a sliding calliper and subsequently all laminates were inspected with ultrasonic C-scan to determine damage size and to obtain indications of damage distribution through the thickness. Inspections by ultrasonic $\mathrm{C}$-scan were performed in a pulse echo mode in an immersion tank with a $5 \mathrm{MHz}$ transducer. The method provides a two dimensional graphical presentation, in 
which the time-of-flight values are displayed to give information on the distance from the top surface to the detected damage.

One specimen of each thickness was put aside for fractographic analysis to further investigate damage distribution through the thickness. To enable fractographic inspections, the specimens were cut through the damage in the width direction and then water polished using waterproof silicon carbide paper with different particle size. The final polish was performed with particle size P\#4000.

\section{Bending and compression tests}

Bending tests were performed in a Zwick $150 \mathrm{kN}$ electromechanical testing rig using a specially manufactured bending rig according to Fig. 2 . The tests were performed with a deformation test speed of $5 \mathrm{~mm} / \mathrm{min}$. The procedure during the bending tests was to load the specimens until a significant drop in load was recognized. The specimens were then unloaded and dismounted from the test rig. The failure was photographed using a digital camera. Some specimens were also subjected to fractographic analysis to determine failure distribution through the thickness. The fractographic analyses included inspection with ultrasonic C-scan and optical microscopy. The impacted side was placed on the compression and tension sides in different tests.

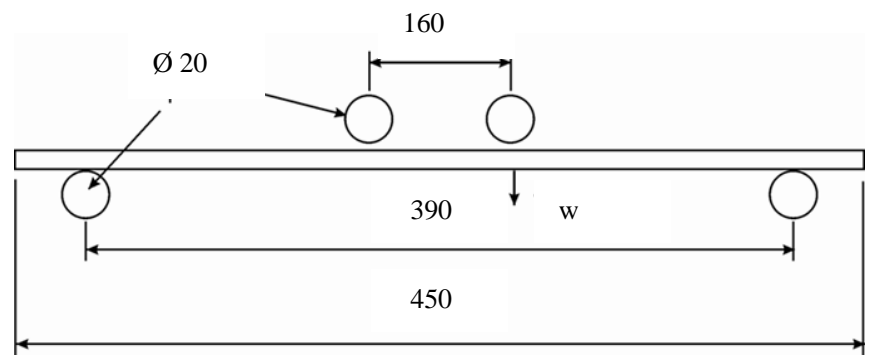

Fig. 2. Bending tests of laminate with impact damage.

Compression tests were performed on specimens with a width of $156 \mathrm{~mm}$ to fit in a rig earlier used at FOI (Swedish Defence Research Agency). Antibuckling devices, depicted in Fig. 3, were used during the tests that were performed in a $1000 \mathrm{kN}$ MTS servohydraulic test rig in load control at a load rate of $2 \mathrm{kN} / \mathrm{s}$.
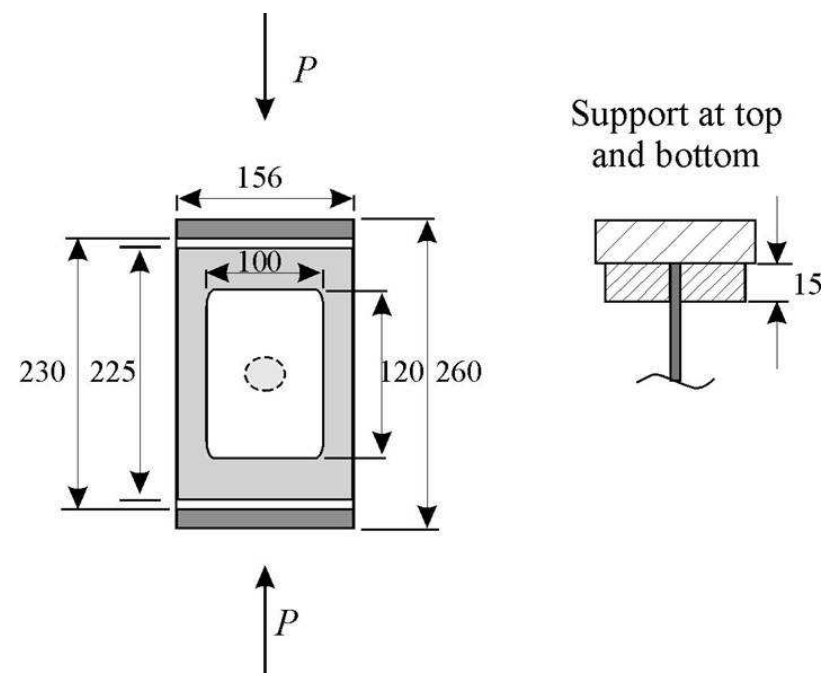

Fig. 3. Antibuckling device used during compression tests. 


\section{DAMAGE AFTER IMPACT}

After impact the residual dent depth was measure using a sliding calliper. The dent depth was found to vary between $0.9-1.1 \mathrm{~mm}$ and $0.1-0.3 \mathrm{~mm}$ for the $4 \mathrm{~mm}$ and $8 \mathrm{~mm}$ laminates respectively.

On the backside of the $4 \mathrm{~mm}$ laminates splitting of the outermost $0^{\circ}$ degree ply due to the impact was recognised. In connection with the splitting, a very large delamination between the outermost $0^{\circ}$ degree ply and the rest of the specimen was observed as shown in the C-scan picture in Fig. 4. As seen in the C-scan pictures the impact damage is distributed through the whole thickness in the $4 \mathrm{~mm}$ specimen whereas damage in the $8 \mathrm{~mm}$ specimen only is observed in the upper third part of the specimen, as a result of high contact stresses present during impact of the thicker laminate.

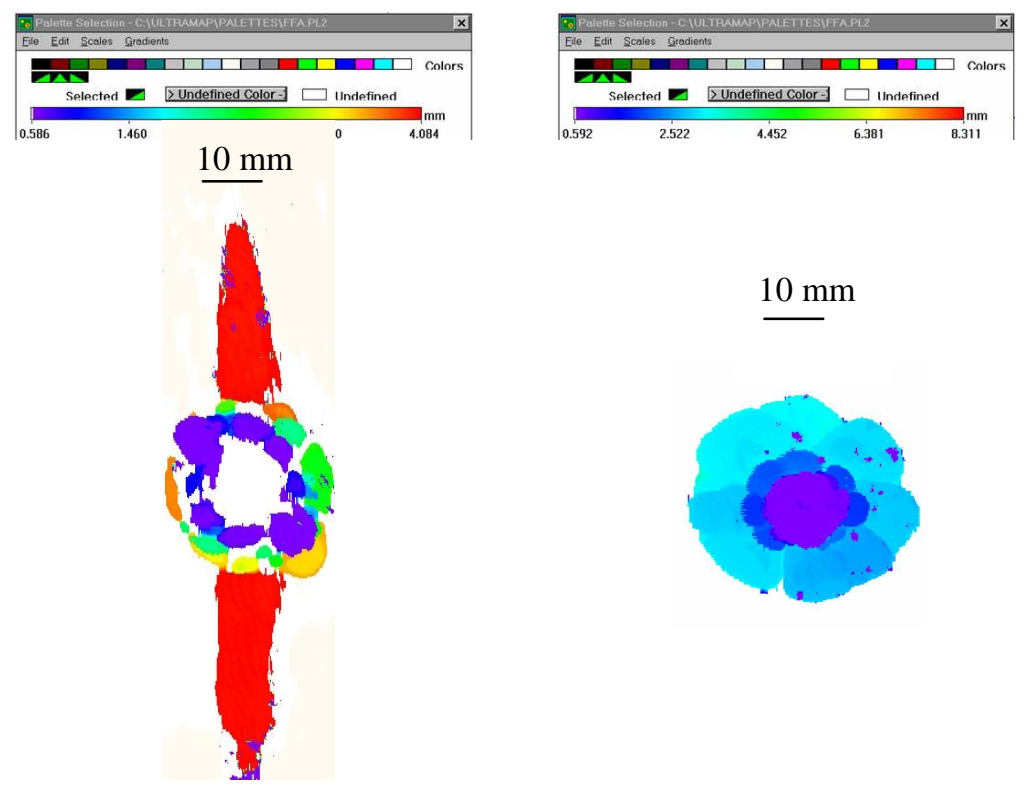

Fig. 4. Damage caused by a $35 \mathrm{~J}$ impact on a) $4 \mathrm{~mm}$ (left) and b) $8 \mathrm{~mm}$ (right) thick laminate

The scatter in size of the damage in the $4 \mathrm{~mm}$ specimens is small; the width varies from 27 to $30 \mathrm{~mm}$, whereas the scatter for the $8 \mathrm{~mm}$ specimens is large, as the width varies from 10 to $30 \mathrm{~mm}$. The reason is that for the $8 \mathrm{~mm}$ specimens a $35 \mathrm{~J}$ impact slightly exceeds the energy threshold level for damage initiation. Fractographic studies of two specimens, one of each thickness, were performed. In the $4 \mathrm{~mm}$ laminate delaminations, fibre failures and matrix cracks could easily be observed through the whole thickness of the specimen as shown in Fig. 5. As seen in the optical micrographs in Fig. 6, indications of damage are, in the $8 \mathrm{~mm}$ laminates, only recognized after the $4^{\text {th }}, 8^{\text {th }}$ and $12^{\text {th }}$ ply from the impacted side. 


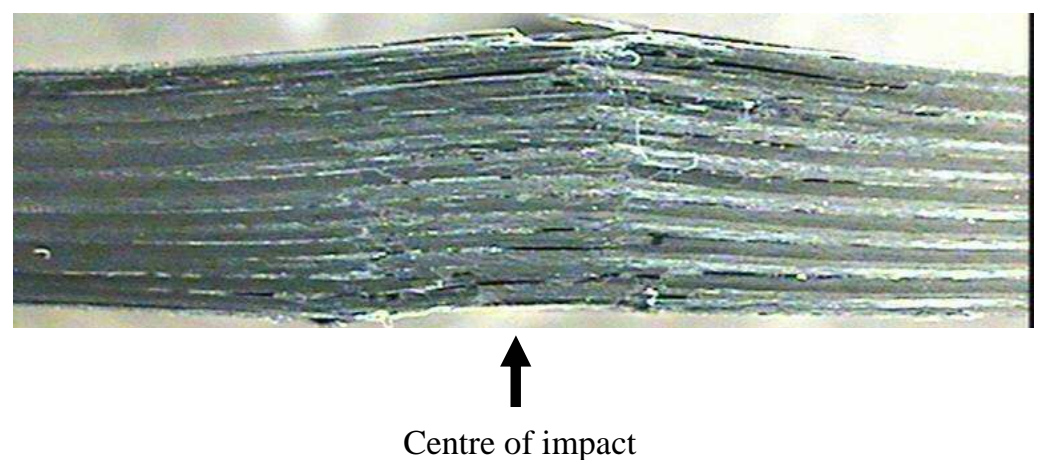

Fig. 5. Impact damage in the $4 \mathrm{~mm}$ laminate.
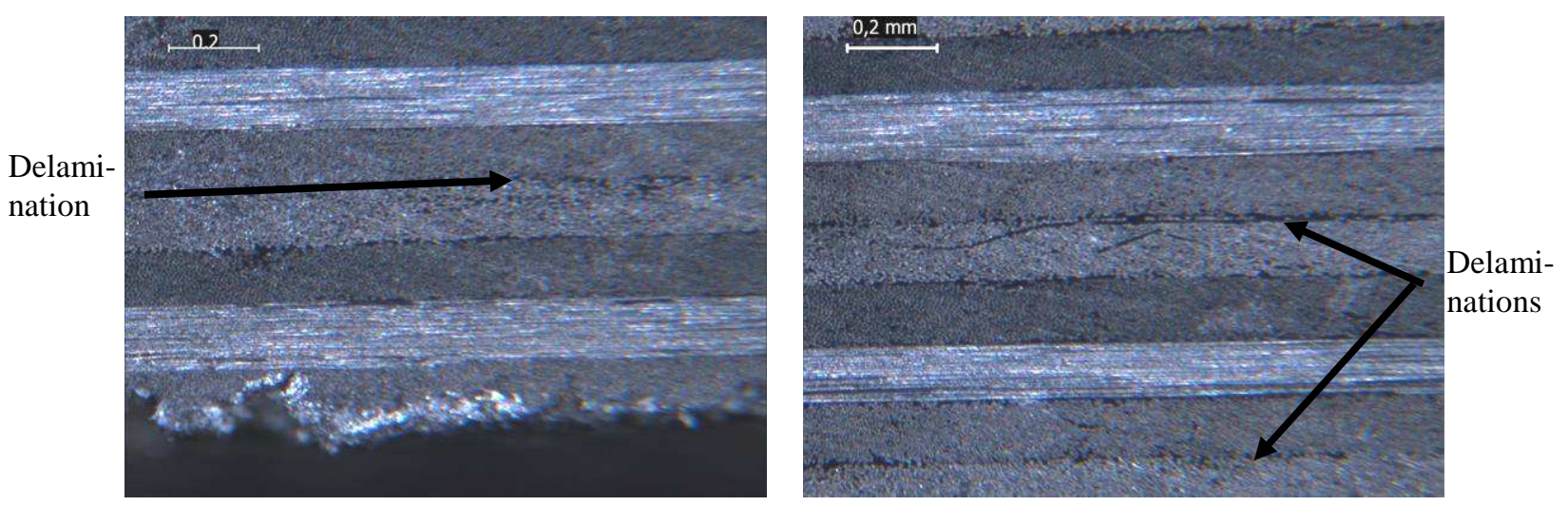

Fig. 6. Damage at the point of impact indicated by te arrows, Left: $1^{\text {st }}$ and $2^{\text {nd }} 90$ degree layers. Right: $3^{\text {rd }}$ and $4^{\text {th }} 90$ degree layers. Layers numbered from the impacted side.

\section{EXPERIMENTAL RESULTS}

During bending tests, the impacted side of the laminates was loaded either in compression or tension to determine effect of damage distribution through the thickness on the bending strength. The study of different thicknesses is motivated as several papers have been published [2, 3, 4, 5] discussing size effect of damage on both tensile and compressive strength of composite laminates. Conclusions from these papers are that there is a significant reduction of the tensile notch strength with increased thickness and also with increased hole size. The compressive strength however decreased with increasing hole size if laminate thickness where scaled on a sublaminate level, i.e. ply thickness where kept constant. An impact damage subjected to bending loads will result in an even more complicated problem as the laminate is subjected to both compressive and tensile stresses from the mechanical loads in combination with three-dimensional stress concentrations from the damage. Consequently it can be assumed that changes of the geometry can affect both failure load and failure mode.

\subsection{Bending tests, thin laminates}

During tests load and displacement were measured with the internal recorders in the test rig. Results are presented in Fig. 7 for the $4 \mathrm{~mm}$ specimens with the impacted side loaded in compression and tension respectively. All results are summarized in Table 1. 
As seen in Fig 7 both maximum displacement and maximum load are lower when the impacted side of the $4 \mathrm{~mm}$ laminate is loaded in tension. This effect can be explained by the fact that the impact damage resulted in larger delaminations on the back side of the thin specimens as well as a residual local geometric deformation of the panel which facilitated delamination buckling of the specimen, see Fig 5.

As seen in Fig $7 b$ typical indications of damage growth in the form of a significant drop in load indicating damage growth was recognized well before the maximum load was reached when the impacted side was loaded in tension. Such behaviour was not recognized when the impacted side was loaded in compression, see Fig. 7a. Testing of one of the specimens with the impacted side loaded in tension was interrupted at a load of $3700 \mathrm{~N}$ to perform fractographic investigations to confirm damage growth as by the load-strain recordings.
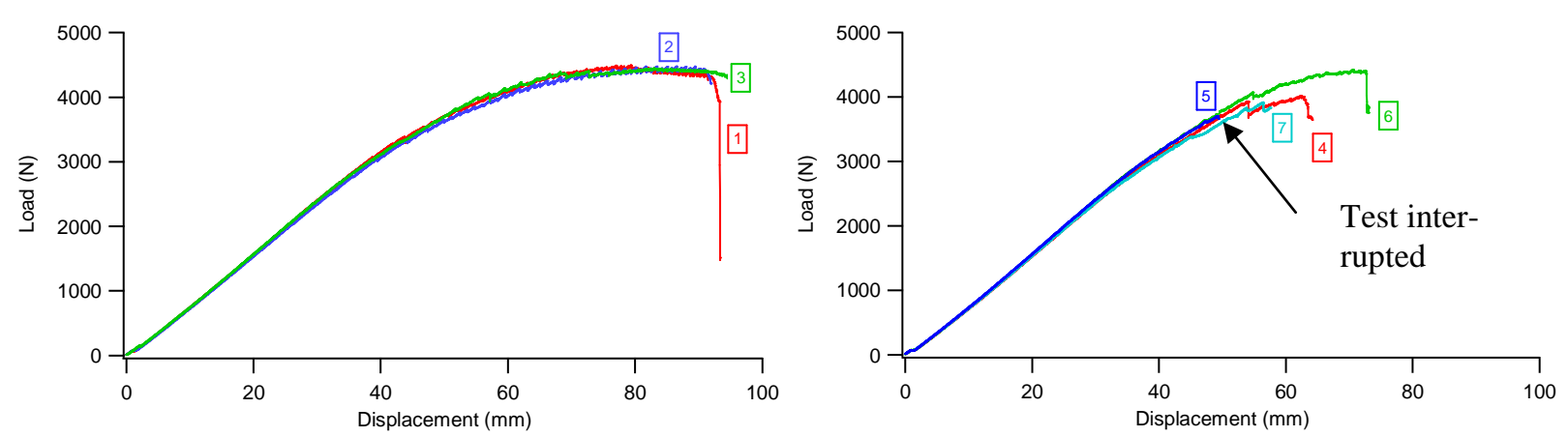

Fig. 7. Load-displacement recording of $4 \mathrm{~mm}$ laminates loaded in bending with the impacted side loaded in compression (left) and tension (right) respectively. The arrow

As shown in Fig. 8 typical failure mode was delamination buckling when the impacted side was loaded in tension, i.e. the back side of the panel with the largest delaminations where loaded in compression. Whereas compressive failure was obtained when the impacted side was loaded in compression.

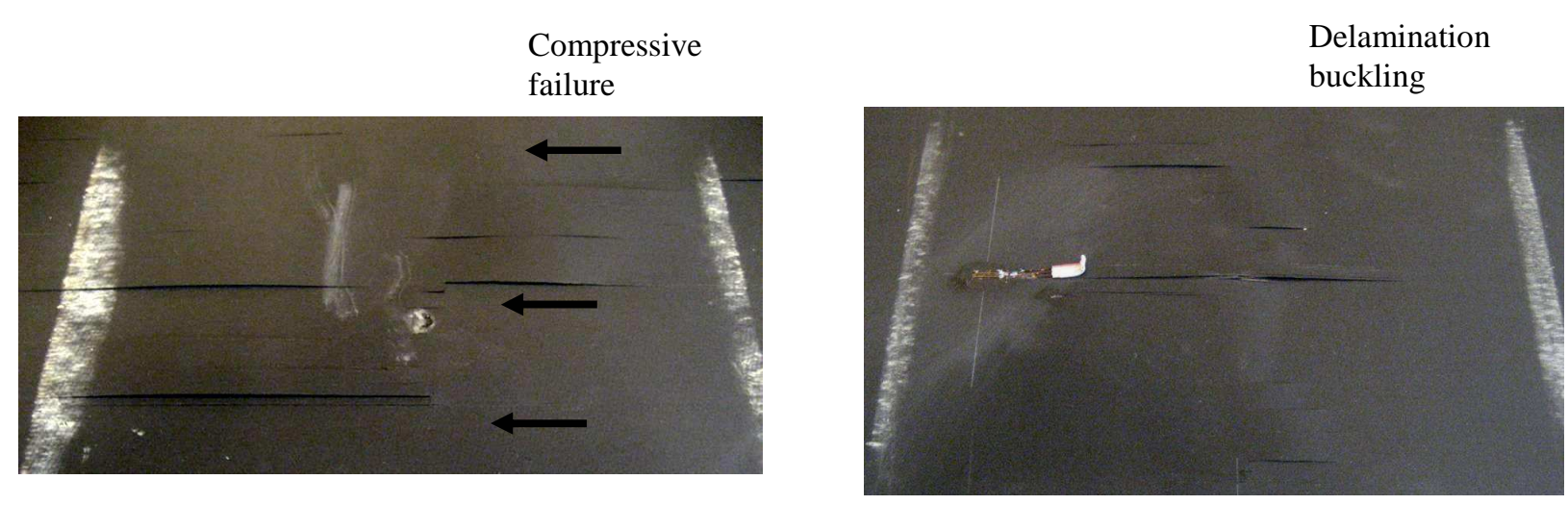

Fig. 8. Compressive failure and delamination buckling when impacted side loaded in compression (left) and tension (right) respectively. 


\subsection{Bending tests, thick laminates}

In contrast, the thick specimens with the impacted side loaded in compression failed at lower loads and lower maximum displacement than those with the impacted side loaded in tension, see Fig. 9 and Table 1. This result reflects the difference in damage distribution through the thickness observed for the $8 \mathrm{~mm}$ laminates compared to the $4 \mathrm{~mm}$ laminates. In the $8 \mathrm{~mm}$ laminates damage has only been detected close to the impacted surface, i.e. the part loaded in compression when the impacted side is loaded in compression.
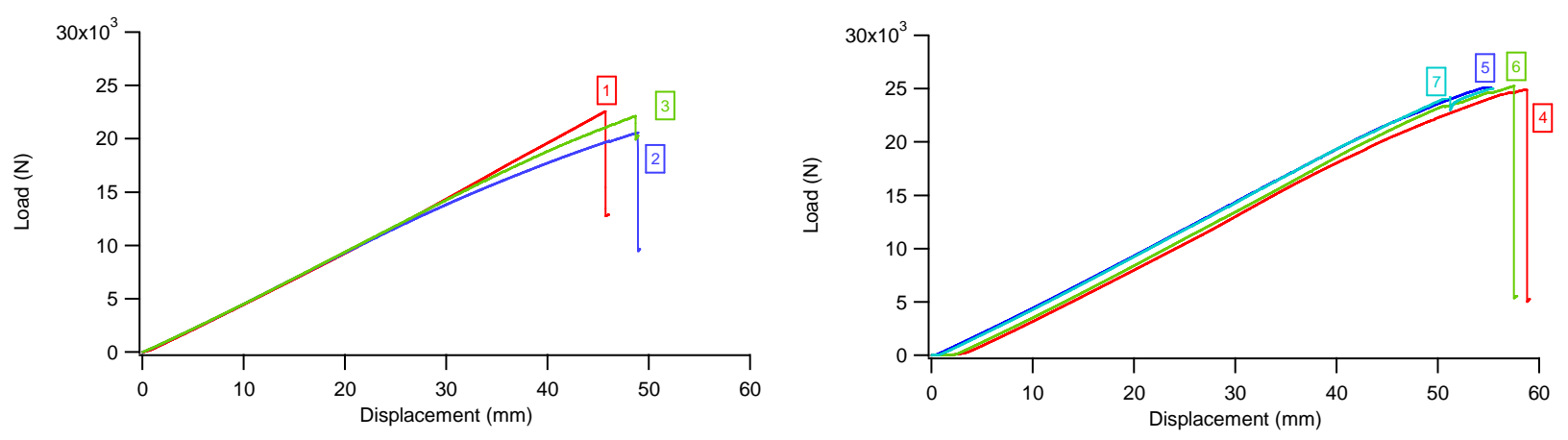

Fig. 9. Load-displacement recording of $8 \mathrm{~mm}$ laminates loaded in 4-point-bending with the impacted side loaded in compression (left) and tension (right) respectively.

Table 1. Summary of the results from mechanical tests.

\begin{tabular}{|c|c|c|c|c|c|}
\hline & & \multicolumn{2}{|c|}{ Loaded in bending } & \multicolumn{2}{|c|}{ Loaded in compression } \\
\hline $\begin{array}{l}\text { Impact } \\
\text { energy } \\
(\mathrm{J})\end{array}$ & $\begin{array}{l}\text { Plate } \\
\text { thickness } \\
(\mathrm{mm})\end{array}$ & $\begin{array}{c}\text { Average failure } \\
\text { moment } \\
(\mathrm{Nmm} / \mathrm{mm})\end{array}$ & $\begin{array}{c}\text { Far field failure } \\
\text { strain } \\
(\%)\end{array}$ & $\begin{array}{l}\text { Failure load } \\
\text { (N/mm) }\end{array}$ & $\begin{array}{c}\text { Far field failure } \\
\text { strain } \\
(\%) \\
\end{array}$ \\
\hline & & \multicolumn{2}{|c|}{$\begin{array}{l}\text { Impacted side loaded in } \\
\text { compression }\end{array}$} & & \\
\hline 35 & 4.16 & 1637 & 0.90 & 982 & 0.45 \\
\hline \multirow[t]{2}{*}{35} & 8.32 & 8017 & 1.19 & 4258 & 0.97 \\
\hline & & \multicolumn{2}{|c|}{ Impacted side loaded in tension } & & \\
\hline 35 & 4.16 & 1511 & 0.83 & - & - \\
\hline 35 & 8.32 & 9154 & 1.39 & - & - \\
\hline
\end{tabular}

For comparison, compressive tests were performed on impacted specimens with both 4 $\mathrm{mm}$ and $8 \mathrm{~mm}$ thickness.

Results are summarised in Table 1 and compared with the specimens tested in bending. The compressively loaded $8 \mathrm{~mm}$ specimens show approximately twice the failure strain as the $4 \mathrm{~mm}$ specimens.

The compressive test of one $8 \mathrm{~mm}$ specimen was interrupted at $500 \mathrm{kN}$ and $600 \mathrm{kN}$. In both cases the specimen was removed from the load rig and inspected with ultrasonic 
C-scan in order to detect if the impact damage had started to grow. No damage growth could however be detected.

Another $8 \mathrm{~mm}$ specimen was first loaded to $500 \mathrm{kN}$, but when no damage growth could be detected by ultrasonic C-scan the specimen was loaded to $680 \mathrm{kN}$ when a snapping sound could be heard from the specimen. After unloading, the $\mathrm{C}$-scan recording indicated damage growth close to the centre of the laminate as shown in Fig. 10.
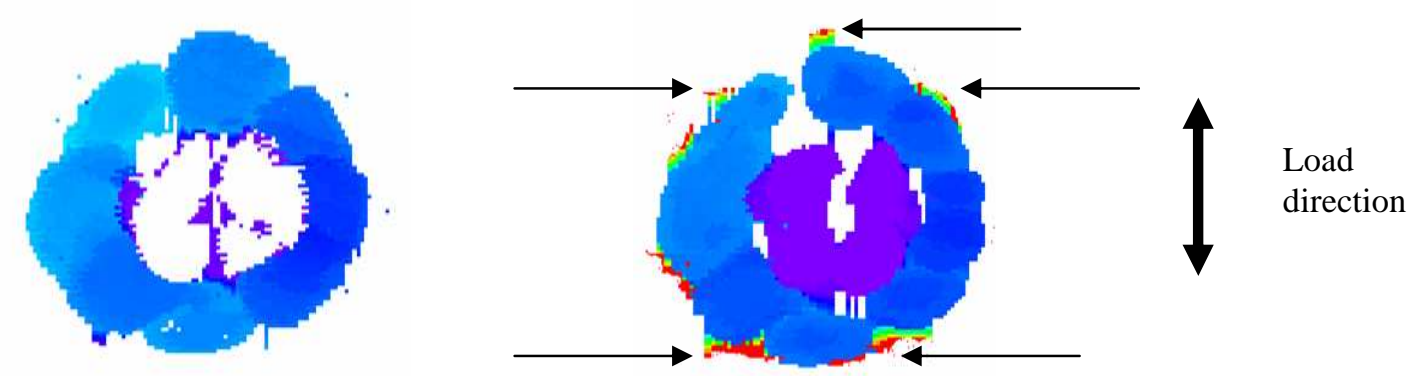

Fig. 10. Indications of damage growth in the centre of an $8 \mathrm{~mm}$ specimen, before (left) and after (right) loading to $680 \mathrm{kN}$.

Subsequently the specimen was loaded to failure and during this test continuously snapping sounds could be heard from a load of $420 \mathrm{kN}$ until final failure at a maximum load of $702 \mathrm{kN}$.

\subsection{Fractography}

In Fig. 11, C-scan recordings from the unloaded and loaded thin specimen, tested in bending, are compared. It can clearly be seen how at least two delaminations close to the back side, the compressive loaded side, of the specimen has grown transverse to the load direction, i.e. in the same way as is well known from compressive loaded impacted specimens [5].
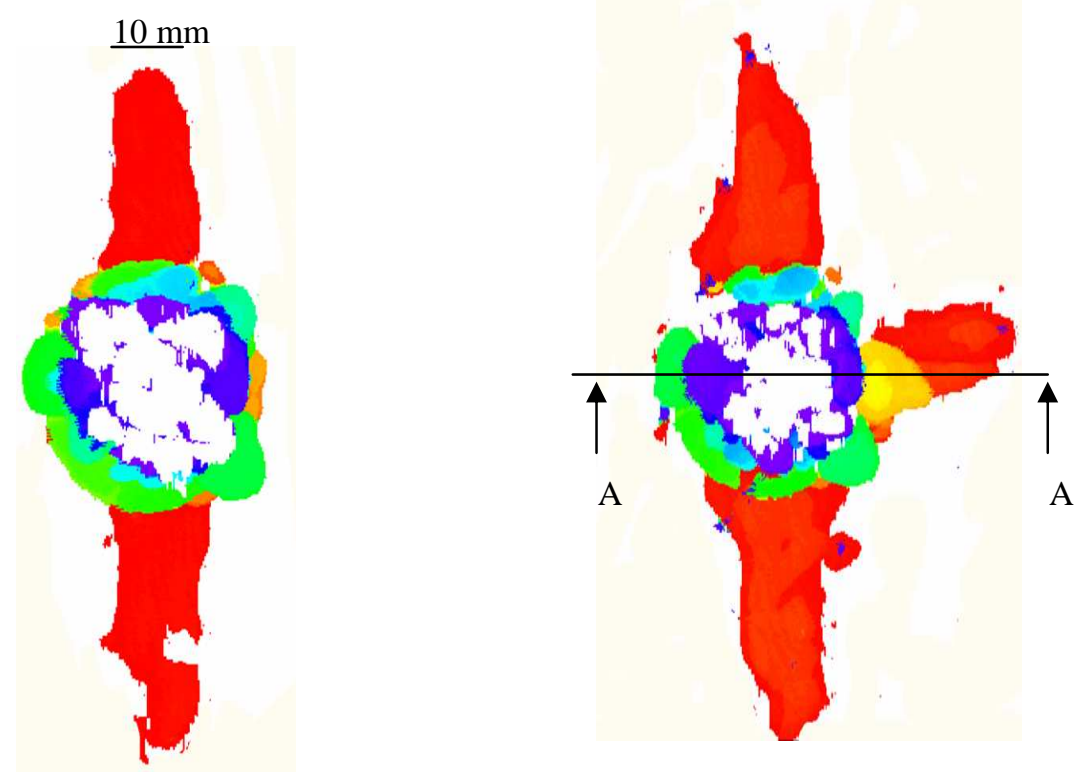

Fig. 11. C-scan of specimen No. 5 before and after bending test. 


\section{CONCLUSIONS}

Four point bending tests of specimens with a $35 \mathrm{~J}$ impact damage were performed and for comparison the same type of specimens were tested in compression. After impact, the damage were characterised using ultrasonic C-scan, and a couple of specimens were also subjected to fractographic analysis. The impacted specimens were tested with both the impacted side loaded in tension and in compression.

As expected the impact damage were more extensive in the thin laminates than in the thick laminates. The damage in the thin laminates were also distributed through the whole thickness, whereas the damage in the thick laminate only could be detected in the upper third of the laminate.

For the thin laminates a $10 \%$ lower failure load was observed when the impacted side was loaded in tension, i.e. the back side with largest delaminations where loaded in compression. For this loading condition the failure was typically delamination buckling, whereas compressive failure was observed when the impacted side was loaded in compression.

For the thick laminates a $15 \%$ lower failure load was recognised when the impacted side, with delaminations, was loaded in compression.

The failure load is more reduced when the side with the larger damage is loaded in compression. As the damage was more extensive in the thin laminates a $40 \%$ higher far field failure strain was obtained in the thick laminates when impacted side loaded in tension.

As expected the far field strain at failure is considerable higher at bending compared to in-plane compression loading. The calculated failure strain of the compressive loaded impacted thin laminates is approximately $45 \%$ lower than the failure strain of the impacted specimens loaded in bending with the impacted surface loaded in tension. The calculated failure strain of the compressive loaded thick laminates is approximately $19 \%$ lower than the laminates loaded in bending with the impacted side loaded in compression.

At strength calculation at design of a structure with a laminate loaded in a combination of in-plane and out of plane loads (bending) there is a potential with a stress methodology that can handle the difference in failure strain, i.e. make use of the higher failure strain in bending. The tests presented in this work are a initial step to increase the knowledge needed to determine such a tool.

\section{ACKNOWLEDGEMENTS}

The work has been founded by Vinnova within the NFFP-program. Parts of this work were performed at FOI (former employer of Sören Nilsson).

\section{REFERENCES}

1. Saab Aerostructures document DDP-RE-030B.

2. Lee J., Soutis C., Measuring the Notch Compressive Strength of Composite Laminates: Specimen Size Effects, Composites Science and Technology, accepted 10 september 2007. 
3. Soutis C., Lee J., Specimen Size Effect on the Notch Sensitivity of composite Laminates Loaded in Compression, $16^{\text {th }}$ International Conference on Composite Materials ICCM16, 2007.

4. Lee J., Soutis C., Thickness effect on the Compressive Strength of T800/924C Carbon Fibre-Epoxy Laminates, Composites Part A: 36 (2005) pp. 213-227.

5. Wisnom M.R., Green B., Jiang W-G, Hallet S.R., Specimen Size Effects on the Notched Strength of Composite Laminates Loaded in Tension, $16^{\text {th }}$ International Conference on Composite Materials ICCM16, 2007.

6. Olsson R., Asp L.E., Nilsson S., Sjögren A., A review of Some Key Developments in the Analysis of Effects of Impact Upon Composite Structures, ASTM, 2000, pp. 12-28. 